\title{
PESQUISA DISCENTE EM BIBLIOTECONOMIA NO BRASIL: ELEMENTOS PARA UMA POLÍTICA EM CURSOS DE GRADUAÇÃO'
}

José Augusto Chaves GUIMARĀES²

\section{RESUMO}

Partindo do resgate dos espaços que têm servido para a discussão da pesquisa discente nos cursos de Biblioteconomia no Brasil e no Mercosul, propõem-se elementos para o delineamento de políticas institucionais na área apresentando ainda o exemplo do curso de Biblioteconomia da UNESP-Marília.

Palavras-chave: Ensino de Biblioteconomia; Pesquisa discente.

\begin{abstract}
Considering the traditional spaces for discussion of student research in Library Education in Brazil and Mercosul (ABEBD, Group Mercosul on Library Education, ANCIB and others), some elements are proposed in order to built institutional policies. In this sense it is presented the UNESP-Marilia experience.
\end{abstract}

Key words: Library Education; Student research.

\section{RESGATANDO ESPAÇOS E IDÉIAS}

Inicialmente há de se registrar a inserção do tema pesquisa no âmbito dos Encontros Nacionais de Ensino de Biblioteconomia e Ciência da Informação (ENEBCIs) enquanto decorrência de um processo de amadurecimento conjunto e crescente das instâncias envolvidas com a questão do ensino de Biblioteconomia no país, haja vista que o tema vem à tona após trabalhadas questões relativas à estrutura curricular (I ENEBCI, 1986), à operacionalização desse fazer curricular, mormente no que tange aos estágios e ao mercado de trabalho (II ENEBCI, 1989), ao delineamento de projetos político-pedagógicos pelas instituições de ensino (III ENEBCI, 1992), aos impactos sofridos pela realidade de ensino do país em virtude do advento de um moderno profissional da informação (IV ENEBCI, 1995), e à discussão das competências e habilidades almejadas para o egresso em um contexto de Mercosul (V ENEBCI, 1998).

Dessa forma, a discussão de uma dimensão investigativa no âmbito dos cursos representa, a meu ver, um efetivo salto de qualidade da área, em busca de um ensino comprometido com a construção do conhecimento e, por decorrência, com a consolidação científica da área.

Nesse contexto, há de se registrar quatro espaços determinantes, espaços esses que de forma articulada têm buscado, no limite de sua competência,

1. Trabalho apresentado no VI ENCONTRO NACIONAL DE ENSINO DE BIBLIOTECONOMIA E CIÊNCIA DA INFORMAÇÃO (Campinas, 30 maio - 2 jun. 2001).

2. Departamento de Ciência da Informação da Universidade Estadual Paulista - UNESP(Marília - SP). e.mail: jaguima@terra.com.br 
atacar essa ponta de iceberg que é a pesquisa na graduação.

Um primeiro espaço a registrar é a própria ABEBD que, desde sua criação em 1967, tem buscado congregar docentes dos cursos de Biblioteconomia ao redor de uma questão central: a qualidade de ensino. Nesse sentido observa-se, desde as atas de reuniões de docentes promovidas pela ABEBD no decorrer das décadas de 60 e 70 até os conteúdos dos ENEBCIs ${ }^{3}$ e dos Seminários Nacionais de Avaliação Curricular ${ }^{4}$, não raras são as menções sobre a necessidade de se investir na pesquisa nos cursos de graduação, seja pela possibilidade de familiarizar o educando com o processo investigativo de sues usuários, seja, mais modernamente, pela busca de um profissional comprometido com o desenvolvimento científico e tecnológico de sua área.

Em integração direta com a ABEBD (e tendo nela um de seus membros nacionais), o Grupo Mercosul de Ensino de Biblioteconomia, criado em setembro de 1996 coma realização do I Encontro de Dirigentes de Cursos Universitários de Biblioteconomia do Mercosul (Porto Alegre) congrega os 43 cursos de Biblioteconomia da região (Argentina, Brasil, Chile, Paraguai e Uruguai), promovendo encontros anuais ${ }^{5}$ para discussão de questões educacionais da área. Cumpre ressaltar que, no âmbito do referido grupo, o tema Pesquisa foi definido como área curricular, na qual desde então vem-se discutindo questões relativas a conteúdos, objetivos, carga horária relativa, marcos teóricometodológicos e capacitação docente. ${ }^{6}$

Igualmente há de se registrar, nesse contexto, o importante papel desempenhado pela nova LDB, que faz menção explícita à questão doa pesquisa no ensino, mormente em se considerando a preocupação em integrar e propiciar espaços comuns entre graduação e pós-graduação, pela ANCIB, que desde 1989 vem buscando criar alternativas para o desenvolvimento da pesquisa no âmbito da área de Ciência da Informação e, ainda, as Diretrizes Curriculares aprovadas pelo MEC que, respeitando os acordos previamente estabelecidos na área em âmbito de Mercosul, deu especial destaque à questão da pesquisa, mas sob uma óptica de transversalidade curricular, tal como tradicionalmente tem esposado a delegação brasileira.

Em termos de literatura e voltando os olhos rapidamente para os espaços voltados para a discussão do ensino de Biblioteconomia a no país e no Mercosul, verificamos que a questão da pesquisa na graduação têm sido objeto de preocupação de alguns autores.

Nesse sentido, Rodrigues (1999 e 2000) tem buscado com muita propriedade discutir a necessidade de se trabalhar a questão da pesquisa como um objetivo pedagógico de nossas Instituições de ensino. Para tanto, defende a autora (2000, p.323):

"A especificidade do aprender com pesquisa, pressupõe, ao mesmo tempo, avanço da ciência e confirmação da prática social.. Assim, unir ensino e pesquisa significa caminhar para que a educação/formação seja realmente integrada, envolvendo estudantes $e$ professores na tarefa de investigar e analisar seu próprio mundo."

3. Eventos de periodicidade trienal que têm por intuito fazer um balanço da situação do ensino de Biblioteconomia do país (e, a partir de 1998, da inserção do país no contexto Mercosul), a partir de temáticas específicas.

4. Eventos instituídos em 1989, sempre em sessão paralela aos Congressos Brasileiros buscando propiciar um espaço para discussões sobre experiências curriculares dos diferentes cursos da área.

5. Set. 1996 (Porto Alegre); nov. 1997 (Buenos Aires); out. 1998 (Santiago); maio 2000 (Montevidéu) e jul. 2001 (Assunção).

6. As áreas curriculares para o ensino de Biblioteconomia no Mercosul são as seguintes: Fundamentos de Biblioteconomia e Ciência da Informação, Organização e tratamento da informação; Recursos e serviços de informação, Gestão da Informação, Tecnologias em Informação e Pesquisa. Ressalte-se que o Brasil tem, tradicionalmente, manifestado sua discordância quanto à inserção das Tecnologias e da Pesquisa como áreas curriculares por entender que as mesmas são transversalidades (ou dimensões) que devem, necessariamente, estar presentes em todas as demais.

Transinformação, v. 14, n ${ }^{\circ}$ 1, p. 55-62, janeiro/junho, 2002 
Guarido \& Oliveira (2000), resgatando a concepção de Demo (1997, p.128) para quem pesquisa é a atitude de aprender a prender, integrando todo,o processo educativo e emancipatório, alertam para a necessidade alertam para a necessidade de se repensar o processo de construção do conhecimento em nossos cursos de graduação, defendendo o educar pela pesquisa como elemento fundamental para que se chegue ao moderno profissional/cidadão almejado por nossos cursos.

Em distintas ocasiões a questão da pesquisa na graduação tem-nos preocupado. Abordando a questão no âmbito do delineamento de elementos filosóficos que pudessem pautar reformulações curriculares na área, referíamo-nos à importância $d a$ pesquisa como elemento de qualidade no ensino de graduação, permitindo ao educando uma vivência da atividade de investigação em um contexto acadêmico (Guimarães, 1997, p.132).

Por outro lado, acreditamos na pesquisa como um compromisso ético a ser honrado pelos cursos por meio de uma visão, exteriorizada por meio de uma postura e resultante em uma ação investigativa (Guimarães, 1998).

E, referindo-nos ao processo formativo do profissional da informação na atualidade, defendemos a existência de quatro dimensões: a profissional, a cidadã, a comunicativa e a investigativa, esta última enquanto

"compromisso da universidade com a postura de reflexão visando à geração de conhecimentos (teorias, metodologias, aplicações) novos, pois o reconhecimento profissional em uma dada sociedade se dá pari passu ao avanço científico da mesma. Em outras palavras, a dimensão profissional só encontra sua plenuitude de conteúdo pela vivencia da dimensão investigativa, sem o qu edeixa de ser formação para ser reprodução de conhecimento". (GUIMARÃES, 2000, p.57).

\section{BUSCANDO ELEMENTOS PARA POLÍTICAS INSTITUCIONAIS}

Tomando-se o ensino de graduação em Biblioteconomia como formação básica que dá direito ao exercício profissional (sendo ainda prérequisito para estudos pós-graduados), em um contexto de indissociabilidade entre ensino e pesquisa em mútua alimentação, deparamo-nos com uma missão - ou, melhor dizendo, uma desafio: fazer do educando / futuro profissional (e ver nele!) um investigador).

Para tanto, creio ser chegado o momento de pensarmos em políticas institucionais de pesquisa discente na graduação em Biblioteconomia como formas de garantir, por um lado, a qualidade do processo e, por outro, sua continuidade.

Nesse sentido, gostaria de trazer à baila um conjunto de elementos que considero importantes para uma reflexão de tal ordem:

a. a inserção clara (eu diria mesmo um privilegiamento!) da pesquisa discente como um dos fios condutores dos projetos político-pedagógicos dos cursos, de modo a distanciarmo-nos dos tentáculos de um ensino reprodutivista e dependente;

b. a formação de massa crítica (capacitação investigativa docente) como elemento de motivação (a questão do paradigma) para a pesquisa discente. Nesse contexto ressalto a imprescindibilidade do testemunho do docente enquanto investigador como, por exemplo, sua atuação em Projetos Integrados de Pesquisa ${ }^{7}$;

c. a definição clara e realista de linhas de pesquisa institucionais (ou departamentais), fruto de uma consciência efetiva das fortalezas e das debilidades de cada curso, fugindo da ingênua (e perigosa!) idéia que todos os cursos formarão profissionais de mesma natureza. Ressalto aqui a importância de as

7. Fica a questão: que poder de persuasão tem o docente que ensina pesquisa sem, no entanto, vivenciá-la? 
linhas refletirem a realidade de pesquisa da instituição, encontrando lastro (sem o que deixam de ser linhas de pesquisa para serem cartas de intenções!) nos projetos e na produção científica de seus docentes e discentes;

d. assunção da vivência (cotidiana!) da pesquisa como carro-chefe da estrutura curricular, eixo horizontal que recebe subsídios de conteúdo das distintas disciplinas e a elas fornece subsídios diretos em termos de instrumental e de novas respostas a antigas questões (por meio da experimentação científica);

e. definição de uma política institucional de incentivo e apoio à pesquisa discente, por meio de posturas como: inserção efetiva em Programas Institucionais de Bolsas de Iniciação Científica PIBIC/CNPq), delineamento de projetos integrados de pesquisa que comportem bolsas de IC, inserção em linhas de iniciação científica de agências regionais (como por ex. a FAPESP), atribuição de um caráter eminentemente científico às atividades integrantes de bolsas de assistência ao estudante ${ }^{8}$ e, ainda, a criação de Escritórios de Pesquisa que possam oferecer apoio aos distintos pesquisadores $^{9}$;

f. a vivência articulada das dimensões teórica (disciplinas de natureza metodológica) e prática (TCCs, monografias de bacharelado, etc) da pesquisa, de modo a que o aluno tenha clara para si a aplicabilidade direta de uma a outra; g. a definição de uma política institucional de divulgação da pesquisa (jornadas e congressos de iniciação científica, revistas de iniciação científica, sites e bases de dados com divulgação de TCCs, participação do aluno em congressos no exterior, etc), de modo a propiciar ao aluno o reconhecimento de sua atividade de pesquisa e, principalmente, dar-lhe subsídios para dar os primeiros passos na construção de um curriculum vitae mais acadêmico;

h. o trabalho pedagógico visando à valorização do produto da pesquisa discente, seja como ponto de partida para estudos pós-graduados (o TCC como germen para um projeto de mestrado), seja como diferencial de competitividade para alguém que ingressa no mercado.

\section{A GUISA DE EXEMPLO}

A título de exemplo dessa concepção, gostaria de compartilhar com os colegas a política de incentivo à pesquisa construída pelo Departamento de Biblioteconomia e Documentação (hoje Departamento de Ciência da Informação) da UNESP no decorrer dos últimos dez anos.

Como passo inicial, investiu-se na capacitação e formação de massa crítica, de modo a propiciar que o corpo docente, uma vez majoritariamente possuidor de título de doutor, tivesse acesso a uma mais amplo espectro de linhas de incentivo à pesquisa. Para tanto, teve-se como política a concessão de afastamentos parciais tendo como premissas: a) propiciar um maior número de docentes concomitantemente em processo

\footnotetext{
8. Especificamente quanto a essa questão, tem-se não apenas a possibilidade de incrementar as atividades de iniciação cientifica da instituição como se estará contribuindo para dar a essas bolsas um significado acadêmico que vai além do mero (e segregador) assistencialismo.

9. Essa idéia de Escritório de Pesquisa foi pela primeira vez implementada na UNESP-Marília em 1996, a partir de um projeto de Mariângela Fujita, sendo o Escritório de Pesquisa o braço operacional da Comissão de Pesquisa da unidade no que tange a todo o apoio logístico às atividades investigativas. Para tanto, o referido órgão dispõe de toda a informação relativa às agências de fomento e aos dinstintos tipos de bolsas e auxílios, oferece apoio quanto ao enaminhamento e acompanhamento de projetos, gerencia o Fundo de Pesquisa da Unidade e coordena atividades voltadas para a obtenção de recursos para apoio à pesquisa na unidade.
} 
de capacitação; e b) garantir que o docente em capacitação não perca, durante esse período, seu contato com a universidade, mormente no que tange às atividades de ensino, de modo a que possa compartilhar com seus alunos esse seu processo de crescimento e amadurecimento científico.

Uma vez vencida essa etapa, partiu-se para o delineamento de linhas de pesquisa departamentais que refletissem as especificidades temáticas dessa massa crítica. Desse modo, procurou-se trabalhar com linhas suficientemente abrangentes que permitissem congregar ao menos três docentes (lançando bases para futuros grupos de pesquisa), dentro das quais definiram-se temáticas mais específicas.

Como terçeira etapa, investiu-se maciçamente em uma política de incentivo à iniciação científica, no âmbito da qual cada docente possuía, perante o departamento, o compromisso de responsabilizar-se por um número $\mathrm{X}$ de bolsas. Para tanto, procurou-se estabelecer ainda uma política perante as agências, de modo que os doutores centrassem seus esforços nas bolsas IC/FAPESP (para as quais o título de doutor é fundamental para a orientação) e os mestres e doutorandos envidaram seus esforços em torno das bolsas PIBIC.

Em seguida, o Departamento procurou apresentar projetos visando ao sistema $\mathrm{CNPq}$, iniciando com bolsas individuais de produtividade em pesquisa (PQ) as quais, com o passar do tempo e o amadurecimento dos projetos, rumou para Projetos Integrados de Pesquisa.

Nesse contexto surgiram os Grupos de Pesquisa do Departamento, os quais foram devidamente cadastrados no $\mathrm{CNPq}$, refletindo a realidade dos projetos integrados e, não raras vezes, os colégios invisíveis que começavam a surgir a partir de contatos inter-institucionais de pesquisadores.

De modo a oferecer suporte a toda essa política, implantou-se o Escritório de Pesquisa, que impulsionou significativamente as atividades investigativas da área bem como permitiu o acesso a uma mais ampla gama de informações acerca dos orga- nismos e modalidades de apoio à pesquisa disponíveis.

Como uma decorrência mais ou menos natural, criou-se, em 1998, o curso de mestrado em Ciência da Informação, aspecto que ofereceu mais um espaço de congregação desse corpo de pesquisadores.

Perpassando todo esse projeto - e, a meu ver, servindo-lhe de elemento propulsor - tem-se o Trabalho de Conclusão de Curso, cujos moldes procuram aproximar-se ao máximo da estrutura do mestrado (exame de qualificação, titulação mínima para banca, requisitos estruturais do trabalho, disciplinas de apoio específico, etc) de modo a que o aluno se torne desde então familiarizado com a estrutura acadêmica, seja para uma futura carreira como docente ou pesquisador, seja para atuar como um profissional mais questionador e comprometido com a construção do conhecimento em sua área.

\section{PENSANDO EM TERMOS DE FUTURO}

Procurando sintetizar as reflexões até então traçadas, desnecessário é reafiramr a importância da pesquisa discente no processo de formação profissional. No entanto, idos são os tempos de iniciativas isoladas de docentes idealistas movendo céus e terras para, não raras vezes, chegar a tímidos resultados.

Se acreditamos que a pesquisa é o diferencial na formação de nosso aluno, se defendemos que a vivência (e não mais o mero discurso) da mesma é condição sine qua non para que esse possa traçar seus próprios rumos e contribuir para o crescimento científico da área, é chegado o momento de pensarmos institucional e estrategicamente, buscando políticas que racionalizem e congreguem esforços dando consistência e visibilidade científica às ações.

Diferentemente de outras áreas, somos privilegiados pelo fato de termos espaços nacionais e internacionais (ABEBD e Grupo Mercosul, por exemplo) para discutirmos conjuntamente tais questões assim como, em verdadeira exceção no âmbito Mercosul, dispomos de uma estrutura pública e privada de apoio à pesquisa, estrutura essa por vezes sub-utilizada. 
Fica a questão: Será que o tema pesquisa discente em Biblioteconomia não poderia ser objeto de um grande projeto de pesquisa com as diferentes instituições de ensino da área, em busca de novos rumos para a área? Não estaria aí um mote para uma ação integrada dos cursos? A ABEBD, com a temática e o desenvolvimento deste VI ENEBCI bem nos deu provas de sua real preocupação a respeito. Cabe a nós, a ação.

\section{REFERÊNCIAS BIBLIOGRÁFICAS}

ABEBD. ASSOCIAÇÃO BRASILEIRA DE ENSINO DE BIBLIOTECONOMIA E DOCUMENTAÇÃO. II Encontro Nacional de Ensino de Biblioteconomia e Ciência da Informação: relatório. Porto Alegre: ABEBD, 1989. 13p. (cópia mimeografada).

ABEBD. ASSOCIAÇÃO BRASILEIRA DE ENSINODE BIBLIOTECONOMIA E DOCUMENTAÇÃO. III Encontro Nacional de Ensino de Biblioteconomia e Ciência da Informação: relatório. Revista Brasileira de Biblioteconomia e Documentação, São Paulo, v. 26, n. 1/2, pp.145-151, jan./jun. 1993.

ABEBD. ASSOCIAÇÃO BRASILEIRA DE ENSINO DE BIBLIOTECONOMIA E DOCUMENTAÇÃO. Moderno profissional da informação: o perfil almejado pelos cursos de Biblioteconomia brasileiros. Porto Alegre: ABEBD, 1998. (Documentos ABEBD; 13).

BRASIL. Leis, decretos etc. Lei no. 9.394, de 20 de dezembro de 1996. Estabelece as diretrizes e bases da educação nacional. Diário Oficial da União, Brasília, v. 134, n. 248, 27 dez. 1996.

BRASIL. Ministério da Educação e do Desporto. Secretaria de Educação Superior. Proposta de diretrizes curriculares para os cursos de Biblioteconomia. Brasília: MEC/SESu, 2000. (Acesso em 19.02.2001 por meio do endereço eletrônico: http://www.mec.gov.br/sesu/ftp/curdiretriz/ informacao/dir.doc

ENCONTRO DE DIRIGENTES DE CURSOS SUPERIORES EM BIBLIOTECONOMIA DO MERCOSUL. Porto Alegre, 28-28 set. 1996. A formação profissional em Biblioteconomia no Mercosul. Porto Alegre: ABEBD, 1996. 3v.

ENCUENTRO DE DIRECTORES DE LOS CURSOS SUPERIORES DE BIBLIOTECOLOGÍA DEL MERCOSUR, 2 / ENCUENTRO DE DOCENTES DE BIBLIOTECOLOGÍA Y CIENCIA DE LA INFOR-
MACIÓN DEL MERCOSUR, 1. Buenos Aires, 27-29 Nov. 1997. La formación profesional en Bibliotecología y Ciencia de la Información en el Mercosur: acuerdos y recomendaciones. Buenos Aires: Universidad de Buenos Aires. Facultad de Filosofia y Letras. Departamento de Bibliotecología y Documentación, 1997. 15p.

ENCUENTRO DE DIRECTORES DE LAS ESCUELAS DE BIBLIOTELOGÍA DEL MERCOSUR, 3/ ENCUENTRO DE DOCENTES DE LAS ESCUELAS DE BIBLIOTECLOGÍA DEL MERCOSUR, 2. Santiago (Chile), 29-31 Oct. 1998. Formación de recursos humanos en el área de información en el Mercosur: compatibilización curricular; competencias del profesional de la información en el Marcosur. Santiago (Chile) : Universidad Tecnológica Metropolitana, 1999.

ENCUENTRO DE ENCUENTRO DE EDUCADORES E INVESTIGADORES DE BIBLIOTECOLOGÍA, ARCHIVOLOGÍA Y CIENCIA DE LA INFORMACIÓN DE IBEROAMERICA Y EL CARIBE EDIBCIC, 5 (Granada - Esapnha, 21-24 Feb. 2000). La formación de profesionales e investigadores de la información para la sociedad del conocimiento: actas del... Granada: Universidad de Granada. Facultad de Biblioteconomia y Documentación, 2000. 506p.

ENCUENTRO DE EDUCADORES E INVESTIGADORES DE BIBLIOTECOLOGÍA, ARCHIVOLOGÍA Y CIENCIA DE LA INFORMACIÓN DE IBEROAMERICA Y EL CARIBE - EDIBCIC, 3 (San Juan - Porto Rico, Ago. 1996). Informe de la Comisión de Pregrado. San Juan: Universidad de Puerto Rico, 1996. 4p.

GIUBILEI, Sônia. Currículo: trajetória de um compromisso. Revista Brasileira de Biblioteconomia e Documentação, São Paulo, v. 18, n. 1/2, pp. 12-19, jan./jun. 1985.

GUARIDO, Maura Duarte Moreira; OLIVEIRA, Ely Francina Tannuri de. A importância da pesquisa na formação do profissional bibliotecário na Faculdade de Filosofia e Ciências da UNESP - Marília. In: V ENCUENTRO DE DIRECTORES Y IV DE DOCENTES DE BIBLIOTECOLOGIA DEL MERCOSUR. Asunción, 24-27 jul. 2001. Actas... Asunción: Universidad Nacional de Asunción, 2001. 10p. (CD-ROM).

GUIMARÃES, José Augusto Chaves. Ensino de Biblioteconomia no Brasil: uma perspectiva histórica dos encontros nacionais promovidos pela ABEBD. Cadernos da F.F.C. (Faculdade de Filosofia e Ciências da UNESP), Marília, v. 4, n. 1, pp. 68-81, 1995. 
GUIMARÃES, José Augusto Chaves. Ensino de Biblioteconomia no Brasil: perspectivas de desenvolvimento integrado para o terceiro milênio. In: ENCONTRO NACIONAL DE ENSINO DE CONTROLE BIBLIOGRÁFICO DOS REGISTROS DO CONHECIMENTO. Belém, 24-25 nov. 1993. /Atas.../. Marília: ABEBD, 1994. pp. 1-30 (cópia impressa)

GUIMARÃES, José Augusto Chaves. Ensino de tratamento temático da informação nos cursos de Biblioteconomia do Mercosul: análise e perspectivas de um core curriculum à luz da organização do conhecimento. Marília: FFC-UNESP, fev. 2001. Relatório parcial de pesquisa apresentado ao CNPq.

GUIMARÃES, José Augusto Chaves. Formação profissional no campo de informação no Brasil: algumas considerações acerca da LDB. In: SEMINÁRIO DE ESTUDOS DE INFORMAÇÃO DA UFF, 2/ SEMINÁRIO DA ANCIB - REGIÃO SUDESTE, 1. Niterói, 3-5 nov. 1998. Anais... Niterói: NEINFO/UFF, 1998. pp. 47-51 (versão eletrônica)

GUIMARÃES, José Augusto Chaves. Moderno profissional da informação: elementos para sua formação no Brasil. Transinformação, Campinas, v. 9, n. 1, pp. 124-137, jan./abr. 1997.

GUIMARÃES, José Augusto Chaves. Moderno profissional da informação: elementos para sua formação e atuação no Mercosul. In: ENCUENTRO DE DIRECTORES, 3 y DE DOCENTES, 3 DE ESCUELAS DE BIBLIOTECOLOGIA DEL MERCOSUR. Santiago (Chile), 29-31 out. 1998. Actas... Santiago, UTEM, 1999. pp. 36-40.

GUIMARÃES, José Augusto Chaves. Moderno profissional da informação: a formação, mercado de trabalho e o exercício profissional. CFB Informa, Brasília, v. 3, n. 2, pp. 6-7, abr. 1998.

GUIMARÃES, José Augusto Chaves. O profissional da informação sob o prisma de sua formação. In: VALENTIM, Marta Lígia Pomim (org.) Profissional da informação: formação, perfil e atuação profissional. São Paulo: Polis, 2000. Cap. 2, pp. 53-70.

GUIMARÃES, José Augusto Chaves. III Encontro Nacional de Ensino de Biblioteconomia e Ciência da Informação: relatório. Revista Brasileira de Biblioteconomia e Documentação, São Paulo, v. 26, n. 1/2, pp. 142-151, jan./jun. 1993.

LIMA, Raimundo Martins de. A construção social da Biblioteconomia brasileira: a dimensão político- pedagógica do fazer do bibliotecário. Manaus: Universidade do Amazonas, 1999.

LUCK, Esther Hermes; RODRIGUES, Mara Eliane Fonseca. III Encontro Nacional de Ensino de Biblioteconomia e Ciência da Informação: relato das participantes. Niterói;/s.c.p./, 1992. 21p.

MUELLER, Suzana Pinheiro Machado. Ensino de Biblioteconomia no Brasil: problemas e perspectivas. In: SIMPÓSIO INTERNACIONAL PROF. PAULO TARCÍSIO MAYRINK, 2. Marília, 6-8 set. 1996.

OHIRA, Maria de Lourdes Blatt. Currículo de Biblioteconomia: resultados dos estudos de compatibilização curricular do Mercosul. Informativo CRB 14a/ACB, Florianópolis, v. 7, n. 4, p. 5, out./dez. 1997.

PIMENTEL, Cléa Dubeux Pinto. I Encontro Nacional de Ensino de Biblioteconomia e Ciência da Informação: conclusões finais e recomendações. Cadernos de Biblioteconomia (UFPe), Recife, n. 11, pp. 83-123, dez. 1989.

POBLACIÓN, Dinah Aguiar; SERRA, Maria Edith Giusti. Núcleo epistemológico do currículo do curso de Biblioteconomia e Documentação. In: POBLACIÓN, Dinah Aguiar (coord.) Ensino de Graduação em Biblioteconomia no Estado de São Paulo: 1989-1991. São Paulo; ECA-USP, 1992. pp. 112-116.

RODRIGUES, Mara Eliane Fonseca. Ensino com pesquisa: uma nova concepção pedagógica para as áreas de Biblioteconomia e Ciência da Informação. In: IV ENCUENTRO DE DIRECTORES Y III DE DOCENTES DE BIBLIOTECOLOGIA DEL MERCOSUR. Montevideo, 24-27 maio 2000. Actas... Montevideo: Universidad de la República, 2000. pp. 317-323.

RODRIGUES, Mara Eliane Fonseca. A pesquisa como estratégia pedagógica para a competência profissional. In: ENCUENTRO DE DIRECTORES, 3 y DE DOCENTES, 3 DE ESCUELAS DE BIBLIOTECOLOGIA DEL MERCOSUR. Santiago (Chile), 29-31 out. 1998. Actas... Santiago, UTEM, 1999. pp. 41-44

SANTOS, Jussara Pereira. A ABEBD e o ensino de Biblioteconomia do MERCOSUL: relatório de atividades da gestão 1997-1998. Porto Alegre; ABEBD, 1998. (Documentos ABEBD; 11)

SANTOS, Jussara Pereira. O ensino de Biblioteconomia no brasil: propostas de integração e harmonização curricular. São Paulo: APB, 1997. (Ensaios APB; 41) 
SANTOS, Jussara Pereira. O moderno profissional da informação: o bibliotecário e seu perfil face aos novos tempos. Informação \& Informação, Londrina, v. 1, n. 1, pp. 5-13, jan./jun. 1993.

SANTOS, Jussara Pereira. Reflexões sobre currículo e legislação na área de Biblioteconomia. Porto Alegre: ABEBD, 1998. (Documentos ABEBD; 14).

SANTOS, Jussara Pereira; NEVES, Iara Conceição Bittencourt das. A formação do moderno profissional da informação: relatório técnico do V Encontro Nacional de Ensino de Biblioteconomia e Ciência da Informação (São Carlos, 6-8 ago. 1998). Porto Alegre: ABEBD, 1998. $11 \mathrm{p}$.

SANTOS, Jussara Pereira; NEVES, Iara Conceição Bittencourt das. Harmonização curricular em Biblio- teconomia no MERCOSUL. Porto Alegre: ABEBD, 1998. 21p. /Relatório técnico do II Encontro de Dirigentes dos Cursos Superiores de Biblioteconomia dos Países do MERCOSUL e I Encontro de Docentes de Biblioteconomia e Ciência da Informação do MERCOSUL. Buenos Aires, 27-29 nov. 1997).

VALENTIM, Marta Lígia Pomim. Assumindo um novo paradigma na Biblioteconomia. Informação \& Informação, Londrina, v. 0, n. 0, pp. 2-6, jul./dez. 1996.

VALENTIM, Marta Lígia Pomim. Profissional da informação: formação, perfil e atuação profissional. In: (org.). São Paulo: Polis, 2000. 